\title{
Different Self Excitation Techniques for Slip Ring Self Excited Induction Generator
}

\author{
Swati Devabhaktuni \\ Associate Professor, GRIET \\ Hyderabad, India
}

\author{
S.V.Jayaram Kumar \\ Professor, J.N.T.U. \\ Hyderabad, India
}

\begin{abstract}
The paper discusses the different possible techniques to self excite the slip ring induction machine working as self excited induction generator. The generated voltage due to self excitation is initiated and sustained with constant value of power capacitors connected across the stator windings. Attention is focused on the influence of different techniques on generator voltage and output power capabilities. The generated voltage of the wind driven self - excited induction generator (SEIG) is mainly depending on the wind velocity fluctuations and load variations. By choosing the proper value of the self excitation capacitor banks achieves the reactive power requirements. In case of squirrel cage induction generator only the excitation capacitance at stator is used to achieve the reactive power requirements. But in case of slip ring induction generators with the different self excitation techniques at the rotor are used to achieve the reactive power requirements and improvement in the voltage build up. In previous literature there is no discussion about the different techniques of self excitation and its effects on the induction generator. These are the new methods proposed for the improvement in voltage build up and can also controls the slip. MATLAB/SIMULINK based work is carried out for $3.5 \mathrm{~kW}$ machine. Proposed methods may be used for low cost variable speed wind energy conversion systems.
\end{abstract}

\section{Keywords}

slip ring, self excited induction generator, different excitation techniques, voltage variation.

\section{INTRODUCTION}

The inherited poor characteristic of the generated voltage and frequency under varying loading conditions has limited the use of the self excited induction generator as a grid quality power feeder. The basic theory and working principles of self excitation in induction machines has been known for a long time[1]. The required magnetizing lagging volt ampere VAR needed to establish the rotating magnetic field in the stator windings is supplied by connecting across the machine terminals three phase power capacitors of a reasonable size. In order to achieve good voltage regulation under different loading conditions, the value of the excitation capacitive reactance must be varied accordingly. In the squirrel cage self excited induction generators the capacitive effect is varied by employing VAR sources which use discrete variations of leading and lagging power electronic circuitry [2]. These configurations could be employed successfully to the wound rotor machine with the rotor windings shorted at the slip rings end. However, as the operating slip is dependent upon the excitation capacitors, load and most importantly rotor impedance, wound rotor induction generators have the flexibility of controlling the generated voltage and frequency by externally varying the rotor impedance (resistance). Added rotor resistance is replaced by static control units, slip energy recovery systems such as Kramer, current source invertors and chopper circuits. Limitations of autonomous induction generator systems where capacitors provide reactive power for self-excitation and steady-state operation are poor load voltage and frequency regulations, limited output power and corresponding load voltage collapse when generator is loaded beyond attainable maximum steady-state output power. Means in practice to counter these limitations include switching excitation capacitors in and out of circuit, VAR generators using thyristor based compensators and the use of power electronic pulse-width modulation (PWM) converters for voltage and frequency regulation. While the use of switched capacitors is cheaper for attaining coarse voltage regulation with no noticeable influence on frequency regulation, PWM based solutions with capability for load voltage and frequency regulations are relatively expensive and less rugged for autonomous generation schemes especially in remote areas[5]. An induction generator equipped with any of these excitation devices may still be susceptible to voltage deexcitation. This paper examines the use of external components at rotor circuit with different techniques to determine how it influences generator steady state and dynamic generator performance. There is also interest in determining whether structural changes in the excitation system lead to improvement of generator overload capability[4].

It will provide good quality power with less harmonic distortion on load side with easy control of voltage and frequency. The unique feature can be added with this concept is that it has a variable additional rotor capacitance, which can be changed by an optically controlled converter, mounted on the rotor shaft. The optical coupling provided at rotor terminals eliminates the need for costly slip rings that need brushes and maintenance. The rotor resistance can be changed and thus controls the slip. This way, the power output in the system is controlled[3]. The range of the reactive power control depends on the size of the variable rotor capacitance.

The system we tested has the following components:

- a wind turbine

- a three-phase, 3-hp,slip ring induction generator driven by the wind turbine

- various sets of capacitors at stator terminals to provide reactive power to the induction generator

- a three-phase external rotor capacitance at rotor terminals

- a rectifier unit

- a three phase load 


\section{SYSTEM DESCRIPTION AND MODEL DERIVATION}

In this paper the various power electronics circuitry used to achieve variable VAR effect at the generator terminals and could be used in wound rotor self excited induction generators are discussed. The main characteristics are summarized as follows.

\subsection{Variable Voltage Variable Frequency Systems}

In this system the power excitation capacitors are large enough to maintain self excitation at maximum load. The generated output voltage and frequency varies with the size of the excitation capacitors, the load and the operating speed. At no load, high voltage is generated due to the oversized excitation capacitance. This could be minimized by stepping the capacitors in a binary ratio from no load to high load. The generated output power is good only to supply insensitive loads such as heaters, or could be converted to dc to charge a battery. Fig. 1 shows such a scheme.

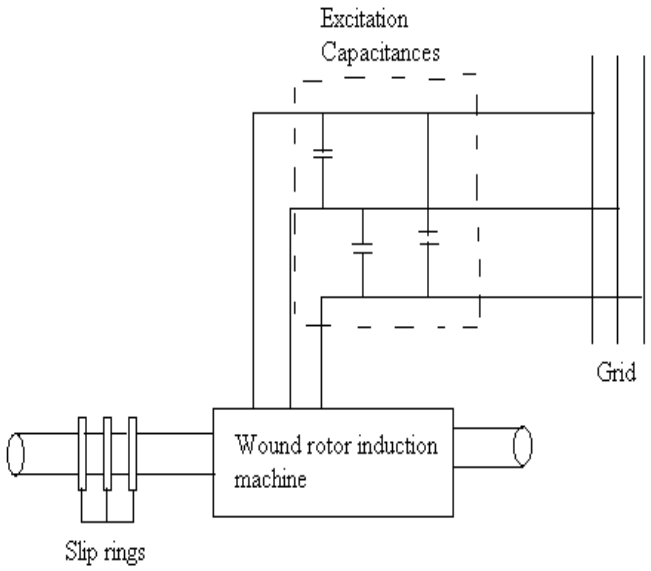

Fig. 1. Variable Voltage Variable Frequency

The response curves of this scheme are as shown in below Figures

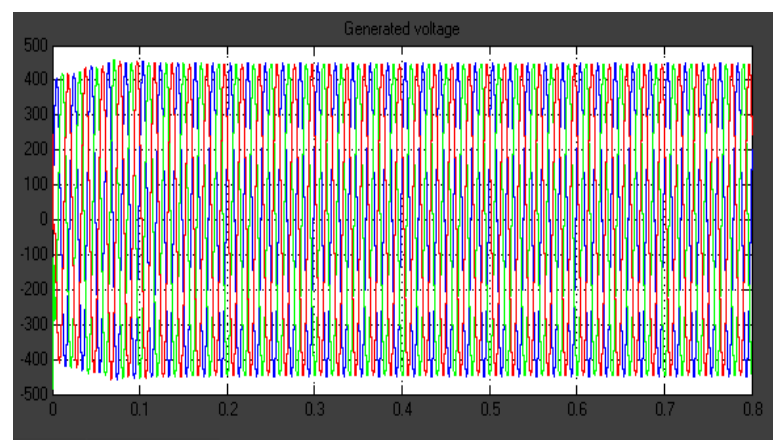

Fig.2.Generated voltage

The voltage generated by SEIG due to this method is 450 volts with a frequency of $50 \mathrm{~Hz}$.Before starting the experiment the slip rings were normally shorted. The excitation capacitance used for this method is $15 \mu \mathrm{F}$.A standard three phase $3 \mathrm{~kW}$ wound rotor induction motor was used for this comparison. The full load ratings of the machine are given in APPENDIX. The grid voltage and the active and reactive power variations are as shown in Fig. 3 \& 4 .
The grid used in MATLAB/SIMULINK here is with 3bus system. Assuming that there are no transmission losses the voltage obtained at the grid is 440 Volts with a frequency of $50 \mathrm{~Hz}$.

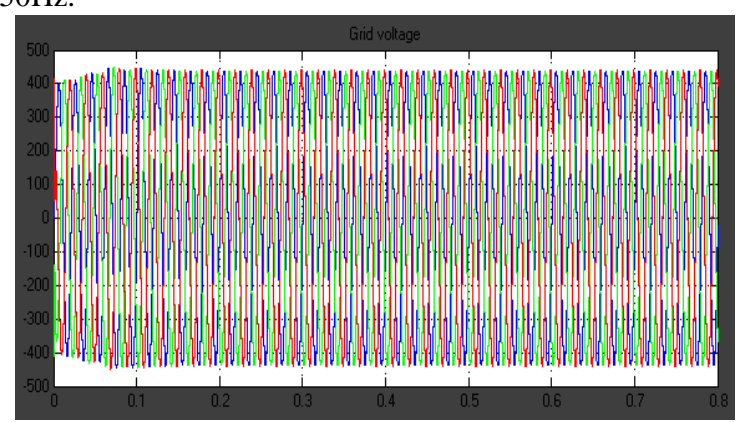

Fig.3.Grid voltage

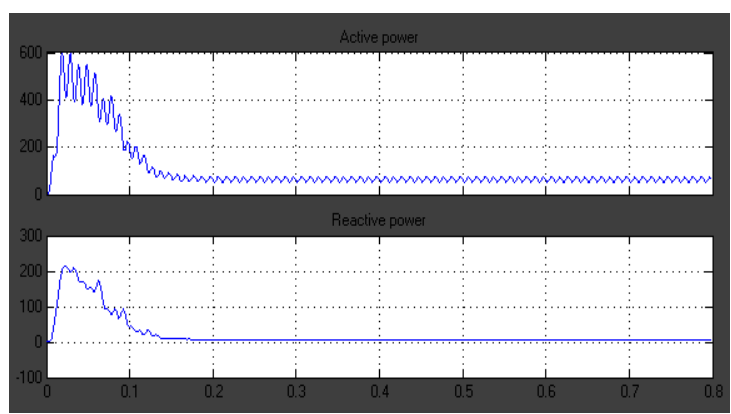

Fig.4.Active and Reactive power.

The active and reactive power is 80Watts and 10VAR respectively. The power factor variation of SEIG is as shown in Fig.5.The power factor obtained with this scheme is 0.79 .

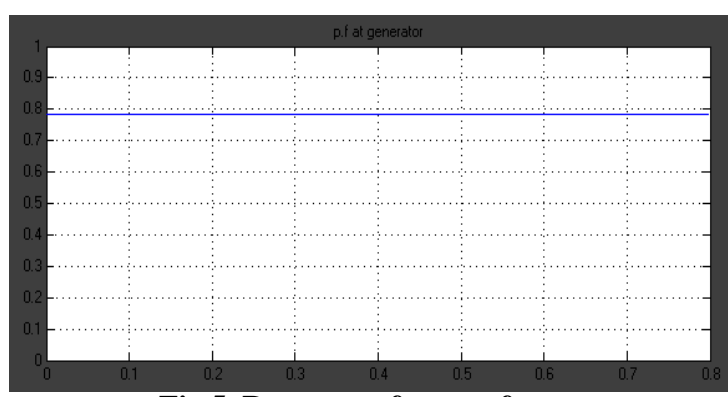

Fig.5. Response of power factor

\subsection{External capacitance at rotor}

In the proposed system, a power generation system consisting of a wind turbine with SEIG connected to the grid and an external capacitance is connected to the rotor is considered. A proposed method based wind driven SEIG fed to grid is shown in Fig.6.

In this system, Turbine coupled with gearbox, generator connected with external rotor capacitance is connected with supply grid. Control of slip (speed) and reactive power is possible with an external rotor capacitance at rotor and stator by adjusting with power electronic converters like chopper with high frequency switching up to $1 \mathrm{kHZ}$. Here ideal system is assumed and external rotor capacitance can be changed according to the requirement as shown in Fig.6.Due to this external rotor capacitance at the rotor the voltage build up is increased than the conventional method discussed in section 
2.1.The disadvantage of this method is the voltage build up may reach a dangerous level with the small change in the capacitance at the rotor.

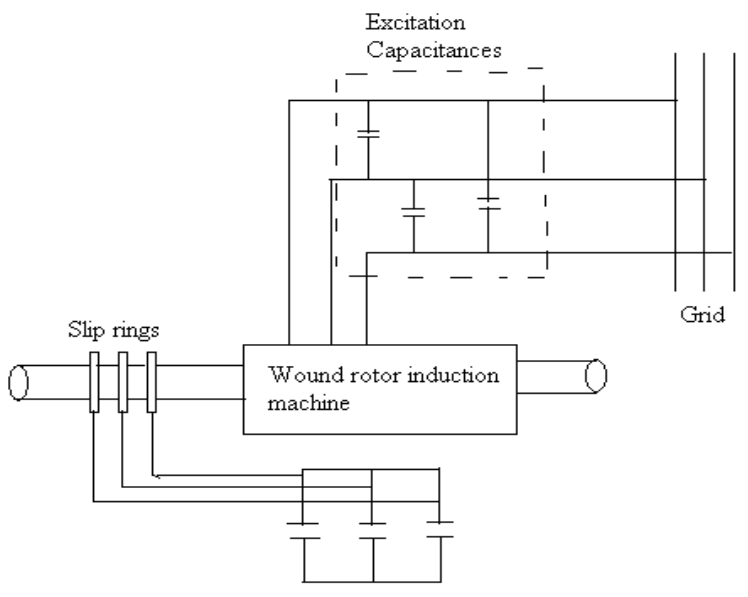

Fig. 6. External capacitance at rotor

The response curves of this scheme are as shown in below Figures.

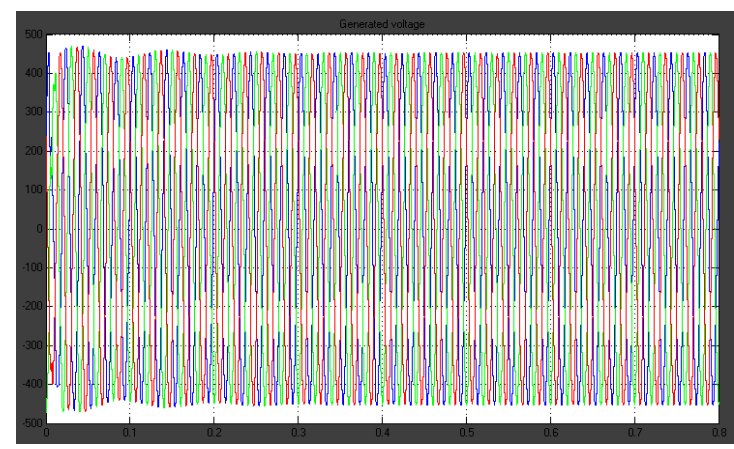

Fig.7.Generated voltage

The voltage generated by SEIG due to this method is 470 volts with a frequency of $50.75 \mathrm{~Hz}$.Before starting the experiment the short circuit was replaced by the external capacitances at the instant the voltage built up at the stator terminals. Self excitation was possible every time the machine was started and there were no problems as in the cases when a teaching type wound rotor machine was tested. The excitation capacitance used for this method is $15 \mu \mathrm{F}$.

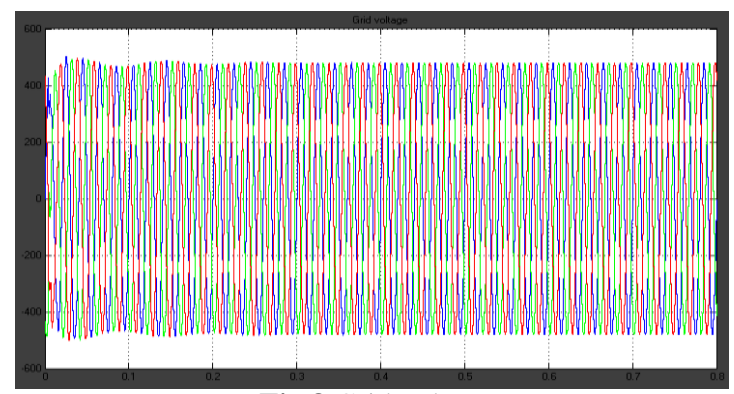

Fig.8.Grid voltage

Assuming that there are no transmission losses the voltage obtained at the grid is 470 Volts with a frequency of $50.75 \mathrm{~Hz}$.With this scheme there is an increase in the speed and the torque. The response of voltage at the grid is as shown in Fig.8

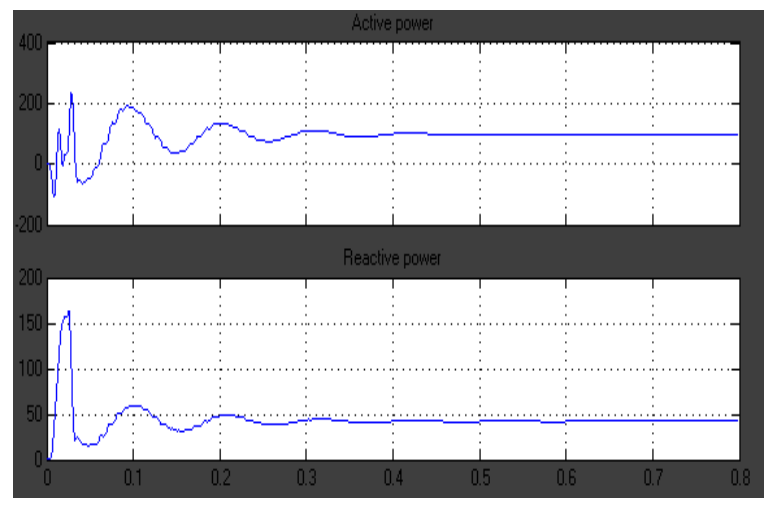

Fig.9.Active and Reactive power.

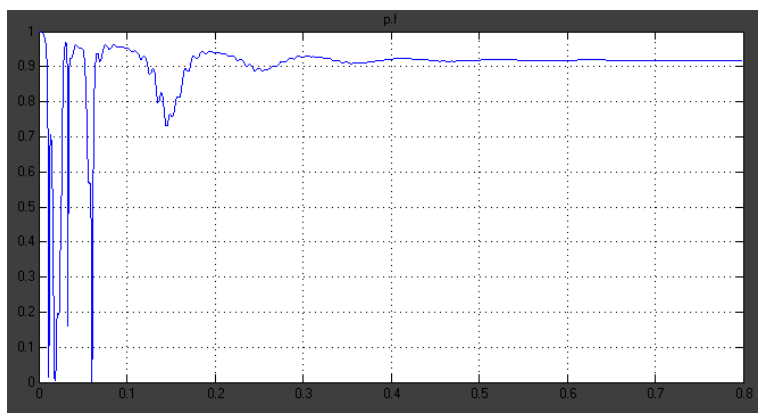

Fig.10.Power factor

Due to the increase in the speed and the torque there is change in the active and reactive power. The active and reactive power is 100Watts and 50VAR respectively. The power factor variation of SEIG is as shown in Fig.10.The power factor obtained with this scheme is 0.9.The active power, reactive power and the power factor are also improved with this method.

\subsection{Regulated Voltage Variable Frequency System}

Here, a static VAR compensator type is connected across the terminal along large fixed values of excitation capacitors as shown in Fig.11. The compensator is either naturally commutated inductive VAR generator or forced commutated VAR generator. In the latter case, the commutation capacitors could also provide the necessary leading VAR to self excite the machine [ 4 ] . Naturally commutated inductive VAR's are simple and cheaper than the forced commutated type. The VAR ratings of any compensator must be rated at full ratings of the stator windings. In either system the generated voltage or level of excitation is controlled by changing the firing angle of the bridge thyristor and thus allowing more or less $\mathrm{dc}$ current to flow through the smoothing inductor. This produces an ac current (fundamental component) at the generator terminal lagging the excitation capacitor current by almost 90 degrees. The generated output voltage could, therefore, be regulated over a wide range of loads. However, the frequency which is a function of speed and rotor impedance will vary. Typical application is limited to supply insensitive loads or as a dc power source. When the controlled rectifier bridge is replaced by current source inverter, three phase power is generated at the output and this adds cost to the system, 
harmonics at the stator terminals and complex control circuitry [5].

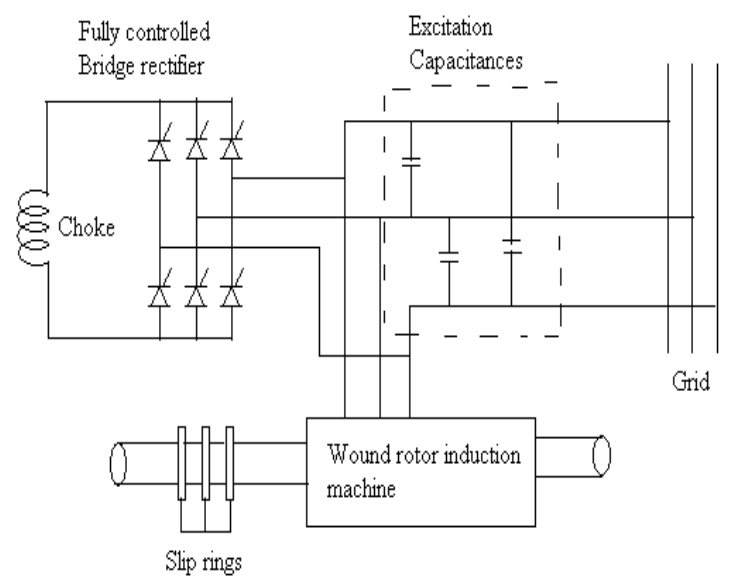

Fig. 11. Regulated Voltage Variable Frequency

The response curves of this scheme are as shown in below Figures.

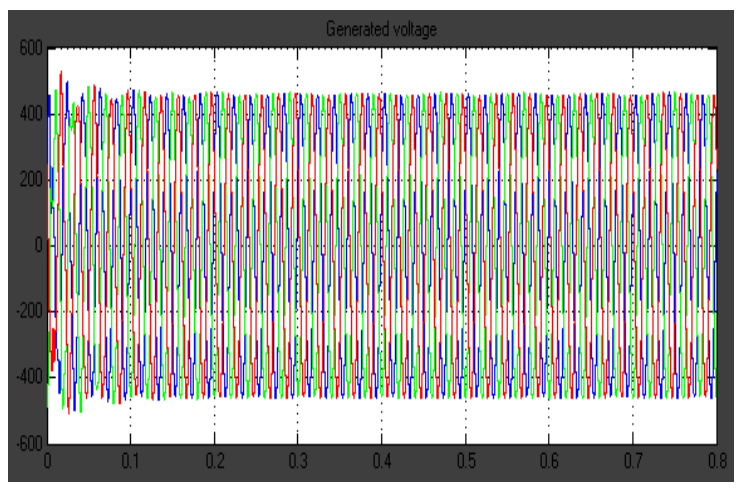

Fig.12.Generated voltage

The voltage generated by SEIG due to this method is 445 volts with a frequency of $50.50 \mathrm{~Hz}$.Before starting the experiment the slip rings are normally shorted. Self excitation was possible every time the machine was started and there were no problems as in the cases when a teaching type wound rotor machine was tested. The excitation capacitance used for this method is $15 \mu \mathrm{F}$.

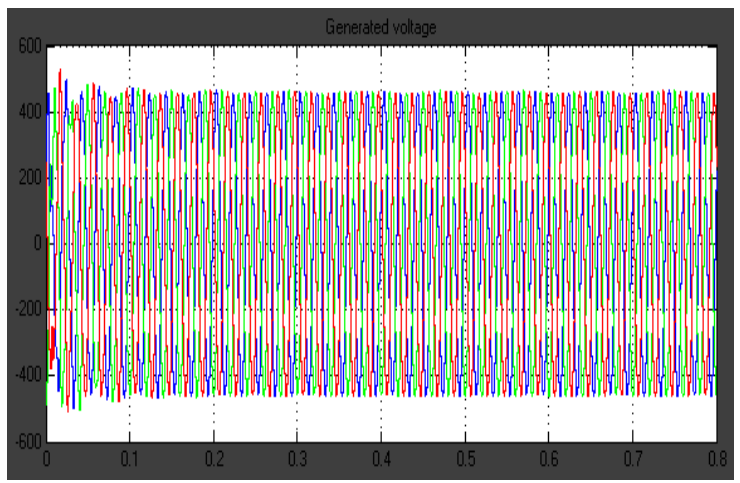

Fig.13.Grid voltage

The voltage obtained at the grid is 435 Volts with a frequency of $50.5 \mathrm{~Hz}$. There is a decrease in the voltage due o the rectifier bridge.With the use of the power electronic devices there will be some losses in the voltage and the power.With this scheme there is an increase in the speed and the torque. The response of voltage at the grid is as shown in Fig.13. The active power, reactive power and the power factor are as shown in Fig. 14 \& 15 .

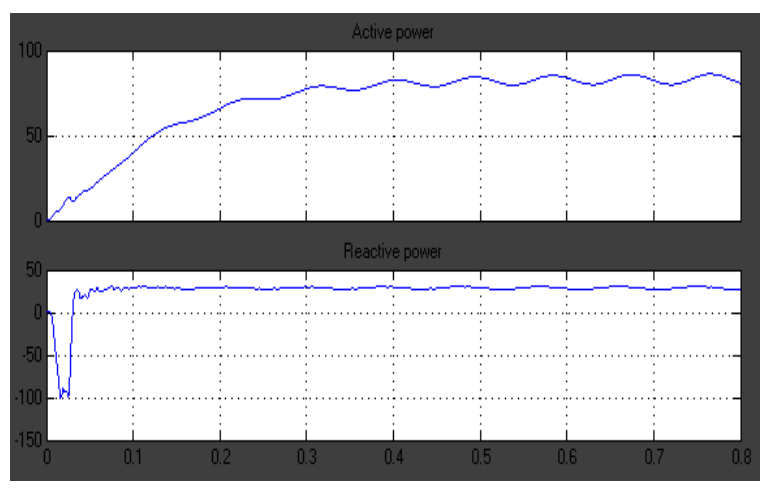

Fig.14.Active and Reactive power

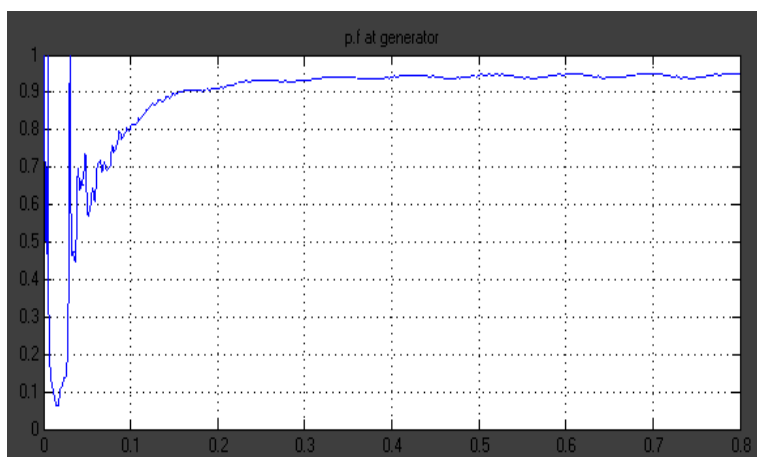

Fig.15.Power factor

Due to the rectifier unit there is decrease in the torque and speed than the previous method discussed in section 2.2. Therfore, there is change in the active and reactive power. The active and reactive power is 90Watts and 35VAR respectively. The power factor variation of SEIG is as shown in Fig.10.The power factor obtained with this scheme is 0.93. The active power, reactive power and the power factor are also improved with this method.

\subsection{Variable Voltage, Regulated Frequency Systems}

In this mode, the stator excitation capacitors are of fixed value with no power controller across the generator terminals. Instead of a short circuit at the slip rings, the rotor windings are connected to a three phase rectifier bridge and are shunted by a resistive load. Fig.16 shows such configuration.

It is worth mentioning that for the power to flow into the rotor windings and out to the rectifier bridge, the rotor rotational speed must be above the synchronous speed. In a conventional motor operation, the power dissipated in the rotor windings and any other controller is a function of air gap torque (mechanical input torque), stator frequency and operating slip. In the self excited generator, controlling the power in the rotor windings and maintaining the air gap torque at a fixed value results in variation of the generated frequency and the operating slip.

However, with the absence of excitation controller, the operating voltage will vary with the load. Therefore, the application of such a scheme again is to supply power to 
insensitive loads. The generated power at the stator terminals will be pure ac with no harmonics, compared to the system described in section 2.3. The rectifier bridge could be replaced by slip energy recovery units such as chopper, current source inverter or cyclo converter and this would allow power to be recovered from the stator as well as the rotor windings. The va ratings of any controller at the rotor side is a function of the operating slip and this is considered to be a second advantage over the system described in section 2.3.

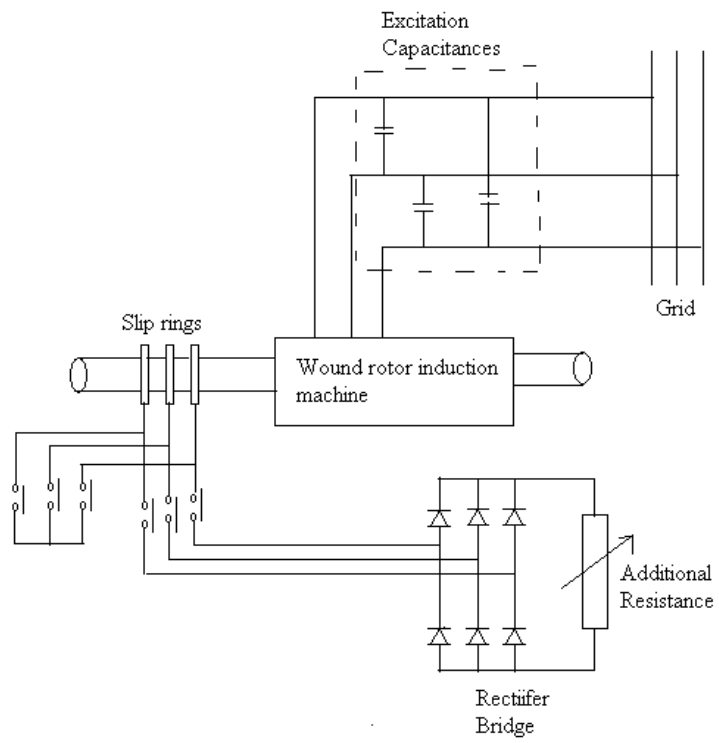

Fig. 16. Variable Voltage Regulated Frequency

The response curves of this scheme are as shown in below Figures.

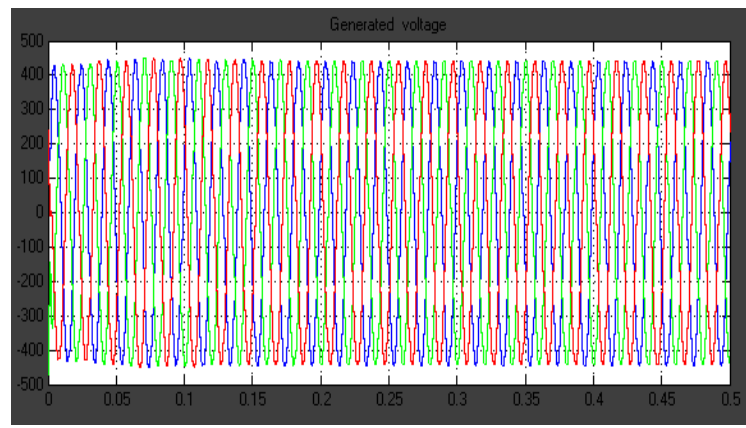

Fig.17.Generated voltage

The voltage generated by SEIG due to this method is 448 volts with a frequency of $50.70 \mathrm{~Hz}$.Before starting the experiment the short circuit was replaced by the rectifier bridge and variable resistor at the instant the voltage built up at the stator terminals. Self excitation was possible every time the machine was started and there were no problems as in the cases when a teaching type wound rotor machine was tested. The excitation capacitance used for this method is $15 \mu \mathrm{F}$.

Several designs of wound rotor induction machines were tested to prove the practicality of varying the rotor resistance, in the proposed method of this section, and its effect upon the generated voltage and frequency for fixed excitation capacitors.
The voltage at the grid is 440 Volts with a frequency of $50.70 \mathrm{~Hz}$. There is a decrease in the voltage due o the rectifier bridge. With this scheme there is an decrease in the speed and the torque when compared with the method in Section2.3. The response of voltage at the grid is as shown in Fig.18.The active power, reactive power and the power factor are as shown in Fig. 19 \& 20.

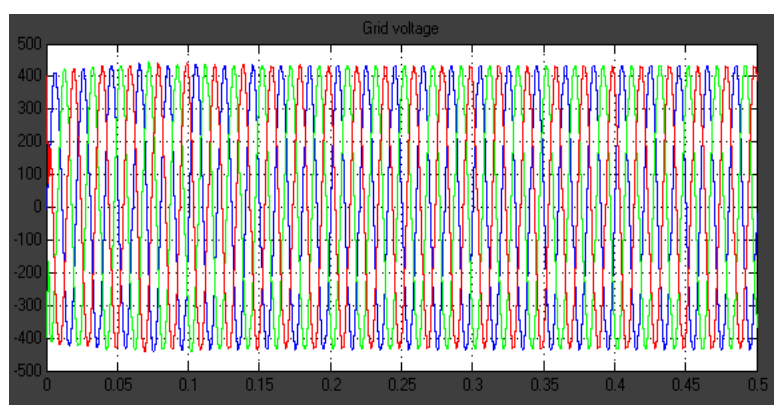

Fig.18.Grid voltage

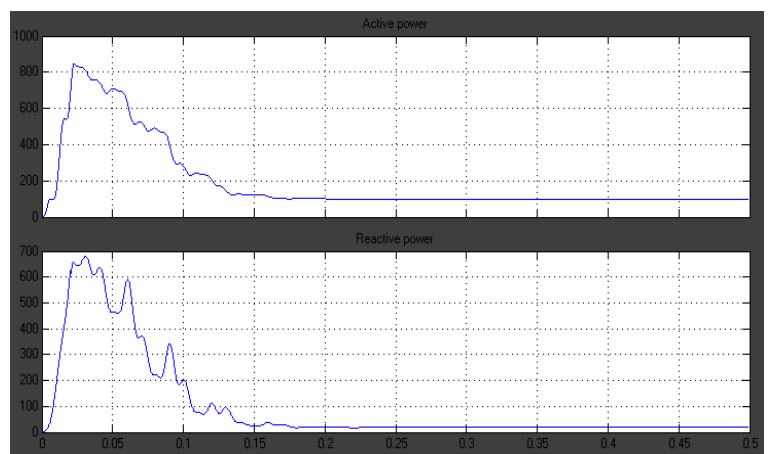

Fig.19.Active and reactive power

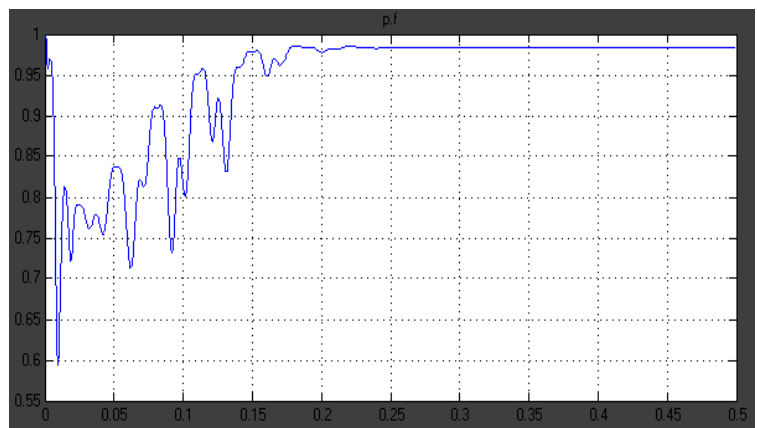

Fig.20.Power factor

The active and reactive power is $100 \mathrm{Watts}$ and $15 \mathrm{VAR}$ respectively. The power factor variation of SEIG is as shown in Fig.10.The power factor obtained with this scheme is 0.95. The active power is improved and the reactive power is decreased and the power factor are also improved with this method.

\subsection{Regulated Voltage and Frequency System}

Combining the systems described in section 2.3 and section 2.4 results in a regulated output voltage and frequency. The generated voltage is continuously regulated by varying the excitation level using VAR compensators along a fixed value of excitation capacitors. Meanwhile, the frequency is kept 
constant by controlling the amount of rotor power either dissipated in a resistor or recovered as a three phase power through sophisticated slip recovery units. Fig. 21 shows a practical circuit of the system. Advantages over the other systems include the ability to generate controllable voltage and frequency with fixed capacitor value.

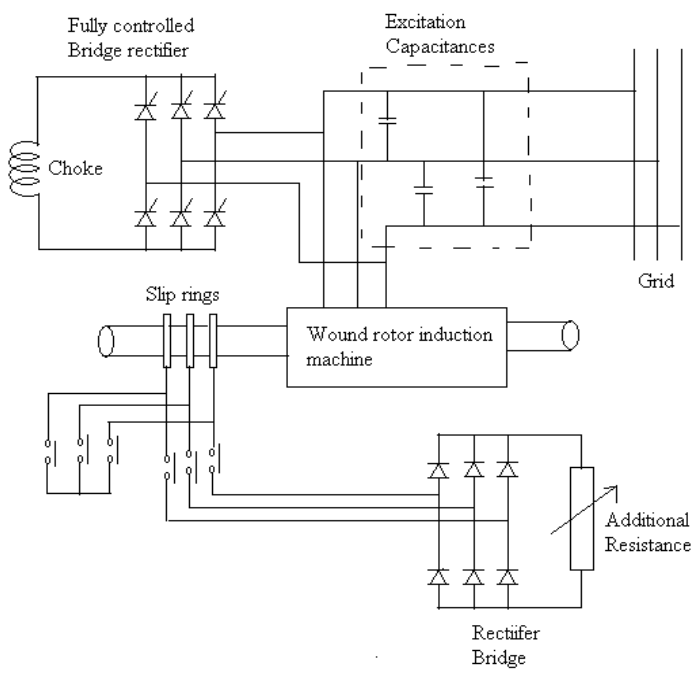

Fig.21. Regulated Voltage and Frequency System

The response curves of this scheme are as shown in below Figures.

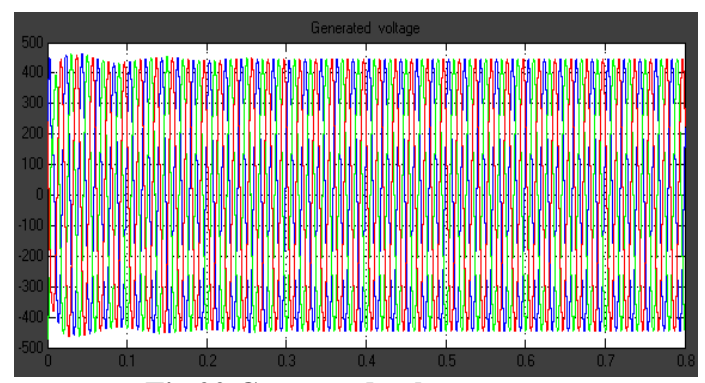

Fig.22.Generated voltage

The voltage generated by SEIG due to this method is 445 volts with a frequency of $50.50 \mathrm{~Hz}$.Before starting the experiment the short circuit at slip rings was replaced by the rectifier bridge and variable resistor at the instant the voltage built up at the stator terminals. The excitation capacitance used for this method is $15 \mu \mathrm{F}$. The generated voltage by the SEIG is as shown in Fig.22

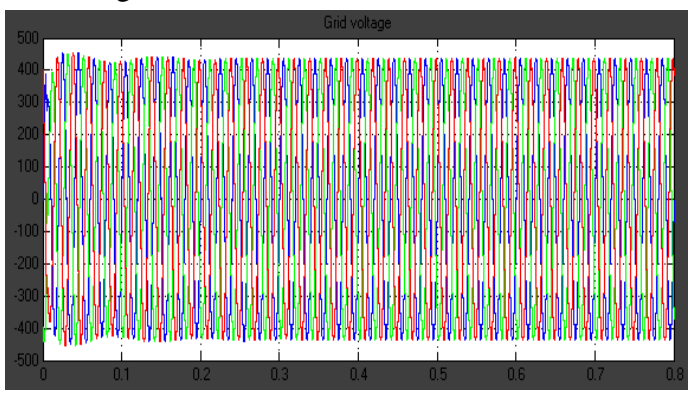

Fig.23.Grid voltage

The voltage at the grid is 435 Volts with a frequency of $50.50 \mathrm{~Hz}$. There is a decrease in the voltage due o the rectifier bridge. With this scheme the speed and the torque are same when compared with the method in Section2.3. The response of voltage at the grid is as shown in Fig.23.The active power, reactive power and the power factor are as shown in Fig. $24 \&$ 25 respectively

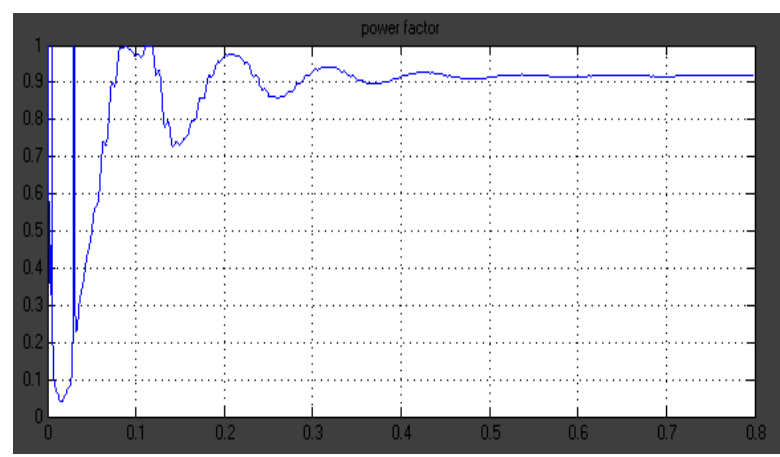

Fig.24.Active and reactive power

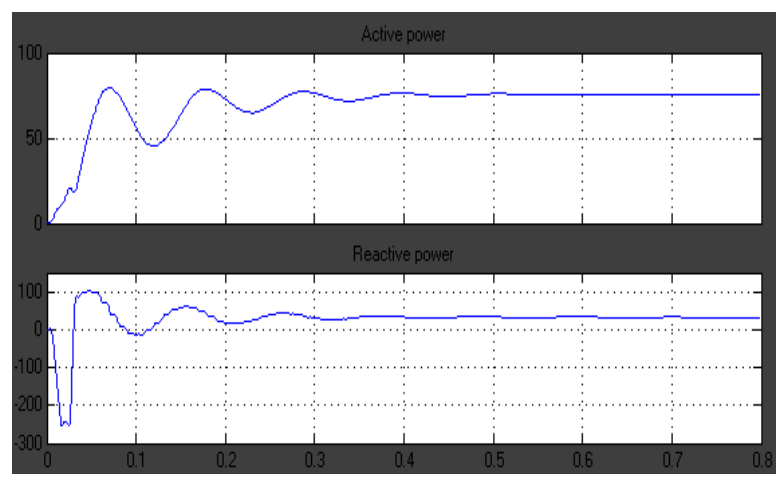

Fig.25.Power factor

The active and reactive power is 85Watts and 30VAR respectively. The power factor variation of SEIG is as shown in Fig.10.The power factor obtained with this scheme is 0.91 .

\section{SELF EXCITATION IN WOUND ROTOR MACHINE}

Self excitation process in the wound rotor machine is very similar to the squirrel cage type. To start the process, the slip rings are first shorted to enable rotor currents to circulate with minimum rotor resistance. With proper excitation capacitors connected across the stator, voltage builds up and is started by the residual magnetism in the core and the initial charge on the capacitor. The operating point is determined by the intersection between the non linear magnetizing characteristic curve and the excitation reactance line. After voltage build up, the short circuit is instantly replaced by the slip energy recovery unit. To simplify the analysis, the system shown in Fig.21 is investigated. At no load, the current flowing into the rotor circuit is almost null indicating an open circuit condition and there is no advantage of adding resistors to the rotor windings. The generator, therefore, will be running just above the synchronous speed. The minimum capacitances required to self excite the machine at no load is approximately given by:

$\mathrm{C}_{\min }=\frac{1}{2 \pi \mathrm{fX} \mathrm{X}_{\mathrm{m}}}$

Where $X_{m}$ is the magnetizing reactance, $\Omega$

$\mathrm{f}$ is the frequency in $\mathrm{HZ}$ 
The steady state response can be predicted for any speed, excitation capacitor, load and rotor impedance using the equivalent circuit shown in Fig.26.

All parameters are shown in referred to rated frequency, in which frequency

$a$ is the ratio of the generated frequency to rated

$\mathrm{b}$ is the ratio of the actual speed to the synchronous speed corresponding to the rated frequency.

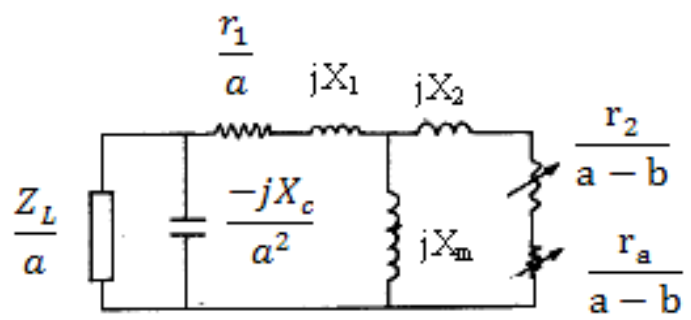

Fig.26.Practical equivalent circuit per phase

Accordingly, the p.u slip is given by

$s=\frac{a-b}{a}$

For operation above the synchronous speed $\mathrm{b}$ must be greater than a. There are different practical procedures to evaluate the unknown parameters of the circuit shown in Fig.26. This leads to solving the circuit for the required stator and rotor currents and in turn the power flow in the machine.

The main characteristics during varying load are summarized as follows:

1. The excitation capacitance must be varied with the load quantity and type, i.e. resistive, inductive or resistive inductive. The excitation capacitor must supply the machine and load VAR requirements. Therefore, large inductive loads require large excitation capacitors.

2. As the generators electrical load changes, the operating slip will also change. This causes variation in the generated frequency and, therefore, a suitable frequency controller must be included.

3. The output generated voltage is governed by:

a. The magnetizing characteristic of the machine at base frequency, e.g. $50 \mathrm{~Hz}$

b. The excitation capacitor size.

c. Terminal load.

d. The operating slip.

To explain the behavior of the generator under varying rotor resistance with constant excitation and varying load, it is assumed that the stator iron and copper losses are of small proportion to the total delivered power. Therefore, the relation between the output power $\mathrm{P}_{\mathrm{g}}$, to mechanical input $\mathrm{P}_{\mathrm{m}}$ to the rotor slip power $P_{s}$.

$$
\mathrm{P}_{\mathrm{t}}=\mathrm{P}_{\mathrm{g}}=\frac{P_{\mathrm{s}}}{\mathrm{s}}=\frac{\mathrm{P}_{\mathrm{m}}}{1+\mathrm{s}}
$$

From which

$$
\mathrm{s}=\frac{\mathrm{P}_{\mathrm{m}}}{\mathrm{P}_{\mathrm{t}}}-1
$$

Thus, the slip is directly proportional to the power in the rotor circuit and is inversely proportional to the load power. From equation (2) the variation of slip will vary the frequency. To probe further, assuming the generator is operating at slip $\mathrm{s}_{1}$, and frequency $\mathrm{f}_{1}$ and excitation capacitor $\mathrm{C}_{1}$ connected across the stator terminals. As the generator load changes, the operating slip changes to $s_{n}$ and frequency $f_{n}$. If $C_{1}$ is to remain constant, the external added resistor must be varied, i.e. varying the power at the slip rings end.

Let at load equal to $\mathrm{P}_{\mathrm{t} 1}$ with slip $\mathrm{s}_{1}$ given by

$$
\mathrm{s}_{1}=\frac{\mathrm{P}_{\mathrm{s} 1}}{\mathrm{P}_{\mathrm{t} 1}}=\frac{\mathrm{P}_{\mathrm{c} 2}+\mathrm{P}_{\mathrm{a} 1}}{\mathrm{P}_{\mathrm{t} 1}}
$$

When load changes to $\mathrm{P}_{\mathrm{tn}}$ with slip $\mathrm{s}_{\mathrm{n}}$ given by $=\frac{\mathrm{P}_{\mathrm{sn}}}{\mathrm{P}_{\mathrm{tn}}}=\frac{\mathrm{P}_{\mathrm{cn}}+\mathrm{P}_{\mathrm{an}}}{\mathrm{P}_{\mathrm{tn}}}$

$\mathrm{P}_{\mathrm{a}}$ being the power dissipated in the added rotor resistance, and Pc being the power dissipated in the machine rotor resistance. To maintain constant frequency then,

therefore

$$
\begin{aligned}
& \mathrm{s}_{1}=\mathrm{s}_{\mathrm{n}} \\
& \mathrm{P}_{\mathrm{sn}}=\frac{\mathrm{P}_{\mathrm{tn}}}{\mathrm{P}_{\mathrm{t} 1}} \mathrm{P}_{\mathrm{s} 1}
\end{aligned}
$$

This will be the new slip power to dissipate in the rotor circuit and any recovery equipment. In section 2.3 the power is dissipated in the rotor resistance and the rest is passed through the rectifier bridge to the added resistor. In such configuration, the effective added resistor seen by the machine and needed to maintain constant slip is given by

$$
\mathrm{r}_{\mathrm{a}}=\frac{\mathrm{V}_{\mathrm{dc}}}{\mathrm{i}_{\mathrm{dc}}}=1.35 \mathrm{~s}_{1} \mathrm{E}_{\mathrm{m}} \frac{\sqrt{3}}{2} \mathrm{I}_{\mathrm{rf}}
$$

Where

$\mathrm{V}_{\mathrm{dc}}$ is the rectified voltage

$\mathrm{E}_{\mathrm{m}}$ is the maximum rotor open circuit voltage and

$\mathrm{I}_{\mathrm{rf}}$ is the rotor fundamental current

The generated voltage for the above conditions is given by

$$
\mathrm{V}_{\mathrm{g}}=\mathrm{I}_{\mathrm{t}} \mathrm{Z}_{1}
$$

Where $\mathrm{Z}_{1}$ is the load impedance

$I_{t}$ is the load current/phase and

As the frequency is constant, the output voltage will be a function of the capacitor reactance and current which is determined by the equivalent circuit shown in Fig. 26. For constant frequency operation and maintaining stator frequency equal to the base frequency, then $a=1$. The solution of the currents in the equivalent circuit will be straightforward knowing the values of the machine parameters including the magnetizing reactance at base frequency. This does not incorporate any mathematical complications in solving the circuit as compared to the cases in section 2.1 or section 2.3.

If a chopper circuit employing thyristor and an external resistor $\mathrm{R}$ is chosen, then the value of the added rotor resistance is varied instantly. The effective resistor value depends upon the circuit configuration used. Generally, the chopper resistance effect (added resistance) is given by:

$$
r_{a}=(1-\beta) R
$$

Where $\beta$ is the chopper duty cycle and equals to the on period divided by the total period.

Apart from using GTO thyristor configuration in the chopper circuit, a complicated commutation circuitry is needed and this adds to the lagging VAR demand and therefore larger excitation capacitance. Chopper circuits with naturally commutated inverse parallel thyristors or triacs could be used as described in reference. An up to date version of the circuit with zero voltage switching technique is under investigation for the systems described in section 2.3 and section 2.4.

To utilize higher efficiency, the slip power may be recovered through complex control circuitry in which the recovered 
power is connected to the load. A cycloconverter could be interfaced between the rotor output and the load. Here the slip frequency is converted to the stator frequency to form a common mains output. The range in which frequency is altered is limited due to the waveform distortion in the cycloconverter. However, such complex circuitry will add cost and distortion to the supplied waveform despite increasing efficiency.

\section{RESULTS AND DISCUSSIONS}

Several designs of wound rotor induction machines were tested to prove the practicality of varying the rotor resistance, Section 2.4, and its effect upon the generated voltage and frequency for fixed excitation capacitors.

Comparison between the different proposed schemes was also investigated practically. A three phase naturally commutated fully controlled thyristor bridge was built for use in section 2.1 and section 2.5. The dc terminal of the bridge is shunted by a large inductance of $340 \mathrm{mH}$. Fixed excitation capacitors of $15 \mu \mathrm{F} /$ phase were connected across the generator terminals along with the controlled bridge. So a static voltage compensator assembly was connected across the terminals as shown in Fig. 11.

A standard three phase $3.5 \mathrm{Kw}$ wound rotor induction motor was used for the comparison. The full load ratings and machine constants at base frequency are listed in Appendix Al. The experimental relations between the generated voltage for variable resistive loads are shown in Fig.27.

However, section 2.4 could be practically used and provide higher percentage of voltage regulation and frequency. For constant voltage and frequency a special control strategy should be adopted for interfacing the control logic of section 2.3 and 2.4 .

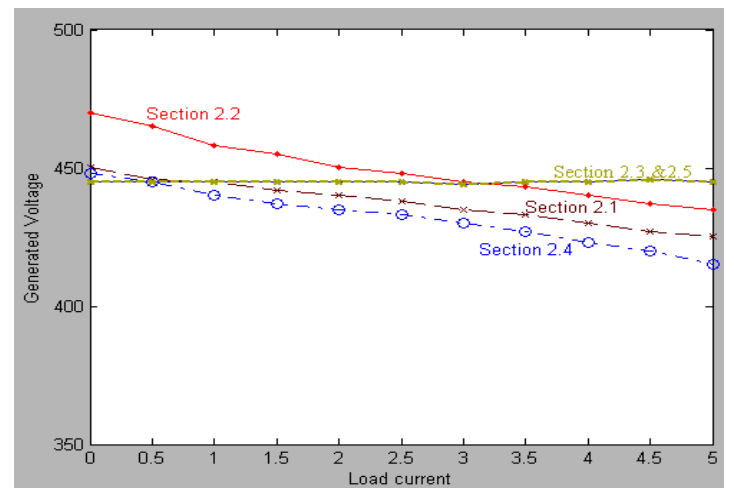

Fig.27. Experimental relation between generated voltage and load current

\section{CONCLUSIONS}

The different schemes to self excite the wound rotor induction machine are presented. Scheme in section 2.4 is the simplest and can provide wide range of voltage and frequency, for constant excitation capacitor. The generated voltage is pure sinusoidal as there is no switching circuitry across the generator terminals. The scheme described in section 2.2 is better method in the improvement in the voltage and due to this method the steady state is achieved more early than the other methods. But while choosing the capacitance proper method should be followed. Other wise the voltage may reach to a dangerous value. Scheme in section 2.3 could be practically used and provide higher percentage of voltage regulation and frequency.

However, for constant voltage and frequency, which in turn simplifies the solution of the equivalent circuit, scheme in section 2.5 is proposed. Poor voltage and frequency regulation was observed in section 2.1.

Further work understands on the different power electronic circuits to replace the rectifier and variable reactor connected at the slip rings. A closed loop control system for scheme in section 2.5 is to be built and practically evaluated.

\section{REFERENCES}

[1] G. A. Smith and K. A. Nigim,"Slip energy recovery techniques for wind energy generators," 4th BWEA conference,Cranefield,UK,April 1982.

[2] C. H. Watanabe and A. N. Barreto, "Self-excited induct ion generator/force-commutated rectifier system operating as a dc power supply,"IEE Proc.,vol.134,pt.B,no.5,Sept.1987.

[3] K. Natarajan, A. M Sharaf, S. Sivakumar and S Naganathan,"Modeline and control design for wind energy power conversion scheme using self excited induction generator,"IEEE Trans.on Energy Conversion,vol.EC-2,no.3,Sept.1987,pp.506-512.

[4] A. K. Tandon, S.S. Murthy and G. J. Bergy,"Steady state analysis of capacitor self excited induction generators,"IEEE Trans.on Power Apparatus and Systems,vol.PAS-103.no.3,March 1984,pp.612-618.

[5] N. H. Malik and A. A. Mazi,"Capacitance requirements for isolated self excited induction generators ,"IEEE Trans-on Energy Conversion,vol.EC-Z,no.1,March 1987,pp.62-69.

[6] S.M.Alghuwainmen,"Steady-state analysis of an isolated self-excited induction generator driven by regulated and unregulated turbine",IEEE transactions on energy conversion,Vol.14,No.3,september1999.

[7] K.S.Sandhu,D.Joshi,"Steady state analysis of selfexcited induction generator using phasor-diagram based iterative model",WSEAS transactions on power systems,Issue12, volume3,December2008.

[8] K.S.Sandhu,S.P.Jain,'Steady state operation of self excited induction generator with varying wind speeds",International journal of circuits,systems and signal processing,Issue-1,volume2,2008.

[9] Mitronikas, E.D., Safacas, A.N. and Tatakis, E.C.,-A new stator resistance tuning method for statorfluxoriented vector-controlled induction motor drivell, IEEE Transactions on Industrial Electronics, Vol. 48 Issue: 6 , Dec. 2001, pp. $1148-1157$.

[10] IEEE Guide for Harmonic Control and Reactive Compensation of Static Power Converters, IEEE Standard 519-1992.

[11] Sewan Choi, and Minsoo Jang, "Analysis and control of a singlephaseinverter - zigzagtransformer hybrid neutralcurrent suppressor in threephasefourwire systems," IEEE Transactions on Industrial Electronics, vol. 54,no.4, pp. 2201-2208, Aug. 2007.

\section{APPENDIX}

The induction machine was three, phase $3.5 \mathrm{~kW}, 415 \mathrm{~V}, 7.5 \mathrm{~A}$, 1500r.p.m, star connected stator winding. The machine was coupled to a D.C.shunt motor to provide different constant speeds. A 3- $\Phi$ variable capacitor bank or a single capacitor was connected to the machine terminals to obtain self-excited induction generator action. The measured machine parameters were:

$\mathrm{r}_{1}=11.78 \Omega ; \mathrm{r}_{2}=3.78 \Omega ; \mathrm{L}_{1}=\mathrm{L}_{2}=10.88 \mathrm{H} . \mathrm{L}_{\mathrm{m}}=227.39 \mathrm{H}$ 